\title{
Factors affecting teaching and learning of Mathematics in the undergraduate mathematics students. A case study at the University of Education, Winneba
}

\author{
Ali Mohammed \\ Department of Mathematics Education, University of Education, Winneba
}

DOI: 10.29322/IJSRP.11.10.2021.p11807

http://dx.doi.org/10.29322/IJSRP.11.10.2021.p11807

\begin{abstract}
The purpose of the study was to investigate the factors that affect teaching and learning of mathematics in the undergraduate students of University of Education, Winneba (UEW) in the Department of Mathematics Education. The study also investigated the challenges that students encounter due to the factors. The study employed case study design. In all, 10 respondents comprising of 6 students from the Department of Mathematics Education from UEW and 4 secondary school teachers were interviewed. The data collected were thematically analysed. The study revealed 13 factors which were categorized into five categories: pedagogical factors, conceptual factors, technological factors, modelling factors and individual factors. Among these factors, the pedagogical factors was considered the most influential of all. These factors if not serious considered, will results in low performance among students in mathematics. The study recommended these factors must be minimized to improve students' performance in mathematics.
\end{abstract}

Keywords: pedagogical, modelling, technological, individual

\section{Introduction}

Mathematics is said to be logical, reliable and a growing body of concepts which makes use of specific language and skills to model, analyse and interpret the world. It is a human activity which involves creativity, discovery of patterns of shape and number, the modelling of situations, the interpretation of data and the communication of ideas and concepts. Unfortunately, several factors have adversely characterize the teaching and learning of mathematics in the undergraduate level of the tertiary institutions in Ghana. According to Leongson (2003) cited in Olive (2014), Pilipino students excel in knowledge acquisition but fare considerably low in lessons requiring higher order thinking skills. This situation is no different in the teaching and learning of mathematics in the undergraduate level. This disappointing condition is evident in the performance of students in national and international surveys on mathematics and science competencies (Olive, 2014). The quality of instruction and effective instructional design according to Dursun and Dede (2004), are necessary to eradicate challenges related to teaching and learning mathematics. According to Piaget cited in Olive (2014), students at formal operational stage are able to apply mental operations not only to concrete objects, but to objects, situations, ideas and concepts that are not directly perceived. Since the learning of mathematics involved operational thought, there is the need to look at the factors that affect teaching and learning of the subject. This study seeks to find out the factors that affect teaching and learning of mathematics in the undergraduate level at University of Education, Winneba.

Mohammed, et al (2012) in their study revealed that teaching practices, teachers' attribution, classroom climate, students' attitude towards mathematics and students' anxiety were factors that influences students' achievements in mathematics. Among these factors, teaching practices was rated the highest and the results showed a significant positive relationship between students' achievement and teaching methods and practices. Murray (2013) in his study also revealed that prior academic achievement, self-efficacy, academic resources, self-regulation 
ISSN 2250-3153

and learning styles were the major factors that influence students' mathematics achievement. Murray (2013) revealed that prior academic achievement, learning styles and academic resources were rated the highest among these factors. Demographic, instructional strategies and methods and individual factors (background knowledge, computational ability, confidence) were considered as factors affecting learning of mathematics and instructional studies was rated the highest factor according to Belhu (2017). Also, according to Gunaseelan and Pazhanivelu (2016), instructional strategies and methods, teacher competency in mathematics education and motivation were the three most influential factors affecting the mathematics achievement and must be considered in the design decision during instructional design. In the field of differential equations for example, factors like epistemological mathematics problem-solving beliefs, belief about usefulness of mathematics, self-regulated learning (SRL) strategies and goal orientations have great potential to enhance differential equations problem ability (Bibi et al., 2007). Other factors included entry behaviour, pass mark, facilities and resources, communication in mathematics (poor knowledge in English Language and poor communication of mathematical facts), absenteeism from lectures, drug and alcohol, career choice, peer influence and mathematical knowledge acquisition (Alfred et al., 2012). The qualification of the teacher according to Tukur and Abimbola (2013) also affect teaching and learning of mathematics. Olive (2014) also found out that mathematics achievements are highly correlated to individual and instructional factors and moderately correlated to classroom management and evaluation factors. Olive (2014) was of the view that individual factor and instructional factor greatly affect achievements in fundamental math and instructional factor is the number one predictor of achievement in contemporary mathematics. Justice, et al (2015) on their study on factors influencing students' mathematics performance in some selected colleges of education in Ghana identified admission grades, social economic status, school background, inadequate teaching/learning materials and lecturer method of teaching as factors affecting teaching and learning of mathematics.

The variety of methods in solving mathematical problems require the need to look at these factors that affects the teaching and learning of mathematics. Students of University of Education, Winneba (UEW) are pre-service teachers who needs to understand every concept learnt for them to become better teachers tomorrow. There is therefore the need to address these factors and the challenges that are associated with them that hinders their conceptual understanding of mathematics. In doing so, the teacher will be able to modify his or her instructional approach to meet the learning needs of the undergraduate students. This will help students to think critically and analytically so that they will be able to apply what they learn to solve real-life problems.

The purpose of this study is to investigate the factors that affect teaching and learning of mathematics in the undergraduate level and the challenges associated with those factors.

The following questions guided the study.

1. What are the factors that affect teaching and learning of Mathematics in the undergraduate level?

2. What challenges are associated with these factors that negatively affect teaching and learning of mathematics in the undergraduate level?

\section{Methodology}

The study employed qualitative research design which is method that focuses on obtaining data through open-ended and conversational communication. The type of qualitative design was case study. This study was conduct in the Mathematics Education Department, University of Education, Winneba (UEW). The population for the study was made up of the entire undergraduate students of the Department of Mathematics Education of University of Education, Winneba (UEW) and mathematics teachers in senior high schools in Efutu, Agona West Municipal in the Central Region of Ghana. Purposive sampling technique was used to select level 400 students of the Department since they have gone through almost all the programs and have also completed their internship program. A simple random technique was then use to select 4 male students, 2 female students and 4 teachers ( 2 per municipal) for the study. Semi-structured interview was used to collect the data from the 10 respondents. The data collected was thematically analysed. 


\section{Results and Discussions}

The results from the study revealed that, thirteen (13) factors that affect teaching and learning of mathematics. The factors are as follows:

1. Instructional strategies and methods

2. Teachers' knowledge in computer and computer applications for mathematics.

3. Students' knowledge in computer and computer applications for mathematics.

4. Perception of teachers on the usefulness of computer in instructional delivery.

5. Students' ability to recall and apply pre-requisite knowledge

6. Students' computational ability

7. Availability of ICT tools

8. Comprehension

9. Motivation

10. Availability of computer applications for mathematics and

11. Socio-economic status (financial constraints)

12. Absenting from lectures

13. Students' attitude towards mathematics

The factors identified were categorized into five: pedagogical factors, conceptual factors, technological factors, modelling factors and individual factors.

\section{Pedagogical Factors}

The pedagogical factors were found to be the most influential of all. The pedagogical factors include instructional strategies and methods, teacher's knowledge in computer and computer applications for mathematics, perception of teachers on the usefulness of computer in instructional delivery and motivation.

Instructional strategies and methods: The instructional strategies and methods was the most essential factor. It includes instructional approaches and methods used during lesson delivery as well as availability and proper use of teaching/learning materials (TLMs). According to the students and the teachers, a very good instructional strategy and method of teaching together with relevant teaching/learning materials aid conceptual understanding. This makes it the most essential aspect of the teaching-learning process. An effective instructional strategy provides meaningful and authentic learning activities to enable students construct or come out of their own methods as well as understanding of the subject matter. This goes a long way to shape students' learning progress and accomplishment. The type of instructional strategy employed by the teacher may help the students to construct their own ideas which will result in the improvement in their conceptual understanding of mathematical concept. This is in line with Belhu (2017) and Gunaseelan and Pazhanivelu (2016) view that instructional strategies and methods provides students with learning situations where they can develop and apply higher-order operations which are critical for mathematics achievements. It also confirms Bloom (1976) assertion that "instructional strategies where students actively participate in their own learning is critical for success". According to Rohrer and Pashler (2007), because students forget much of what they learn, they should be made to benefit from learning strategies that yields long-lasting knowledge. The findings from the study suggest that effective instructional strategies improve students learning process and helps students to reason critically that leads to very good acquisition of knowledge.

The challenges associated with inappropriate instructional strategies and methods are (1) lack of conceptual understanding of Mathematics on the part of the students which leads to shortterm retention, (2) the inability of students to apply concept learnt to other areas, (3) short-term memory on the side of students, (4) poor knowledge acquisition, (5) poor students' performance on Mathematics and also (6) demotivation in students.

\section{Teacher's knowledge in computer and computer applications}

for mathematics: The results from the interview revealed that there are numerous topics in mathematics that requires a reallife demonstration which are unfortunately difficult to demonstrate. Close to the real-life demonstration is the use of computer simulations. But unfortunately, most of the teachers have inadequate knowledge in the use of computers and are not familiar with computer applications that will help in the 
demonstration. The results from the interview showed that, because most of the teachers have limited knowledge on the use of computers and computer applications for mathematics, they result in using writing board illustrations which are not good enough. So, in conclusion, it can be said that, lack of adequately trained teachers in the use of ICTs in teaching is a major factor affecting teaching and learning of mathematics. This is in line with Amuchie (2015) assertion that inadequate knowledge on the use of computer by teachers contributes to poor performance of students in Mathematics.

According to Enuku and Enuku (1999 \& 2000), an ICT driven learning environment is important for the children. Enuku and Enuku (1999 \& 2000) were of the view that ICT integration in teaching will invariably give rise to new instructional techniques and will makes the students engage in individualized learning. This situation they said, gives students access to tools that adjust their attention span and provides valuable immediate feedback to literacy enhancement.

\section{Perception of teachers on the usefulness of computer in} instructional delivery: The responses from the interview show that most of the teachers believe that the use of computers (calculators - programmable calculators especially, tablets, etc) does not support conceptual understanding of the subjective matters. The teachers' view was that, these gadgets only produce answers and does not give detail procedures and steps that led to the solutions. These responses clearly indicate how some teachers have under-estimated the usefulness of computers in the teaching/learning process. Responses from the teachers indicated that their primary use of computer is for graphical and statistical work as well as documentation but not for teaching even though they sometimes used for presentation in the classroom. This confirms Michael (2006) findings that the primary uses of the computer are for graphical and statistical work, with the spreadsheet and a graph-drawing package being the two most commonly used software. These perceptions about the teachers have also demotivated them in their quest to integrate ICT into the teaching and learning processes. The challenges associated with this factor is the lack of conceptual understanding on the part of students and lack of proper motivation on the part of the teachers to learn and use computer during teaching
Motivation: Motivation was categorized as both pedagogical and individual factor. A good motivation prepares students to open their minds so that they can learn. In Ghana's current education system, the challenges associated with the study of mathematics require disciplined study, concentration and motivation. The ability to relate what is learned to real-life applications could be enhanced if students are well motivated during the teaching and learning process. It is therefore imperative that the motivation of teachers and students is not underestimated. The process of motivation stems from stimulation which is turns followed by an emotional reaction that lead to a specific behaviour response (Bed, 2017). The task of the teacher as an instructor is to create an environment for students to actively engage in mathematical thinking and reasoning activities. These according to Carr (1996) help students see mathematics as an area which requires exploration, conjecture, representation, generalization, verification and reflection.

Low interest in mathematics, discouragement, poor performance, and low self-efficacy in mathematics are some of the challenges associated with lack of motivation in students. When students are discouraged in their course to pursue mathematics, it leads low self-efficacy which in turn leads to poor academic performance in the subject.

\section{Conceptual Factors}

The conceptual factors include the students' ability to recall some pre-requisite knowledge and students' computational ability.

Students' ability to recall some pre-requisite knowledge: The study revealed that, most of the students were unable to recall and apply previous relevant knowledge which are pre-requisite to mathematics. For example, most of the students were unable to apply their knowledge on ordinary differential equations, differential and integral calculus, in finding solutions to partial differential equations. Forgetfulness was the major key issue in this scenario. Most of the students for example could not link boundary-value problems in ordinary differential equations to 
the partial differential equations when its application was needed in solving heat and wave problems for example. Students' inability to recall pre-requisite knowledge leads to poor conceptual understanding.

Computational ability: Computational ability is a conceptual factor as well as a modelling factor. Computational ability which was referred to as arithmetic ability by Gunaseelen and Pazhanivelu (2016), consist of skills and techniques such as manipulation of mathematical knowledge and concepts in the manner that transforms their meaning and implications

In finding solutions to some first-order semi-linear and quasilinear mathematics for example, it is very important to recognize how to re-write the resulting characteristic equations in different form ("algebraic manipulation") so that it can easily be solved. For example, students in solving the characteristic equation of a first-order PDE like

$$
\frac{d x}{x\left(y^{2}+u\right)}=\frac{d y}{-y\left(x^{2}+u\right)}=\frac{d u}{\left(x^{2}-y^{2}\right) u}
$$

could not recognized that for any equivalent fractions $\frac{a}{b}=\frac{c}{d}$ it is always true that

$$
\frac{a+c}{b+d}=\frac{a}{b}=\frac{c}{d}=\frac{a-c}{b-d}=\frac{c-a}{d-b}
$$

This confirms Gunaseelan and Pazhanivelu (2016) view that "computational ability (arithmetic ability) allow students to interpret, analyse, synthesize, generalize or hypothesize the facts and ideas of mathematics".

\section{Technological Factors}

The technological factors include students' knowledge in computer and computer application for mathematics, the availability of ICT tools, teachers and students' knowledge in computer and computer application for mathematics and the availability of computer application for mathematics.

The Availability of ICT tools: An ICT driven teaching and learning is very important in our instructional delivery systems. This publication is licensed under Creative Commons Attribution CC BY.
Simulation and graphical representation of concepts are very important during teaching and learning in the classroom. But the inadequate ICT tools have made demonstration of ideas and its subsequent practice by the students very difficult. Every demonstration in a classroom should be followed by hands-on activity but the inadequate ICT tools serves as a barrier to these hands-on activities. Students' view on the availability of the ICT tools was that instructors' demonstration should be followed by hands-on activity but unfortunately that has not been the case.

According to Amuchie (2015), even though television and film appeal to the audio-visual faculties of users, the computer is able to activate the user's sense of sight, hearing and touch. It has the capacity to provide users with higher interactive potentials to develop their individual intellectual and creative capabilities. The challenges associated with lack of computer applications to mathematics are inadequate classroom practices and students' inability to present most especially three-dimensional graphical representation of solutions.

\section{Students' knowledge in computer and computer application}

for mathematics: Knowledge in the use of computer and computer applications for mathematics is essential in modern day mathematics due to the emerging of modern technologies in this century. Some of the equations in differential equations for example, which comes out from the real-life problems have no analytic solution. In this case, there is the need to result to numerical integration in which precision is a key issue. Students' knowledge in computing and the use of computer applications in mathematics like MATLAB, GeoGebra, etc is very essential in this case. Sometimes, the number of iterations required is so large that, only computers and applications capable of such issues are required.

Availability of computer applications for mathematics: The use of computer applications in simulation and graphing of solutions help students to understand the concept underlying mathematics. However, the difficulties in getting these relevant applications for teaching and learning contributes to the setbacks in the teaching and learning process. Students were of the view that they do not have these applications that could have been used to simulate or demonstrate most of the concept in the absence of real-life demonstrations. 
By using educational software (computer application), teachers' roles are significantly changed since the very organization of different classes changes (didactics-methodology components include methods, forms, principles and organizing of the teaching process with all phases of the teaching process: the processing of new materials, repetition, exercises, and testing of taught and acquired materials) (Metodički, 2011).

\section{Perception of teachers on the usefulness of computer in} instructional delivery: Educational systems around the world are increasingly under pressure to apply new ICT tools to their curriculum to provide students with the knowledge and skills they need in the 21st century (Hue and Ab Jalil, 2013). There is significant relationship between teachers' perception towards ICT integration into Teaching-learning process and the factors that encourage ICT usage. This indicates that the teachers' perception towards ICT integration into teaching-learning process improves if ICT usage is encouraged and vice versa (Mewcha \& Ayele, 2015). The results from the interview revealed most of the teachers and students have the perception that, computers are very difficult to use and the only easy thing they can use them for are for the typing. It was further realized that, most of the teachers cannot use the presentation applications to create their own presentations and also cannot create needed animations. They believe this can only be done by the people they are tagged as "computer genius". It was realized that, most of them learnt courses like computer application to mathematics in their colleges and universities just to obtain marks.

\section{Modelling Factors}

Comprehension and computational ability were classified as the modelling factors. Other modelling factor includes computer application to Mathematics.

Comprehension: Comprehension in this study refers to one's ability to read and understand the problem presented. It is a wellknown fact that mathematics is not just about addition, subtraction, multiplication and division of numbers and variables but it has its application in the field of science, engineering, economics and so on. When it comes to the application of mathematics, an individual should be able to read and understand the problem before he or she will be able to model the problem into a mathematical statement or equation. For this reason, comprehension is a key factor in the learning of mathematics. It was realized in the study that, some of the students have difficulties in the interpretation and analysis of the questions when it comes to application questions. According to the students, they sometimes have difficulties in interpreting some of the problems most especially when it comes to problems involving application of the concept learnt. They have challenges in comprehending the problems which leads to their inability to form the mathematical model out of them.

Research have shown that, how students experience situations affects their problem-solving processes and so the comprehension of the situation is a relevant factor when solving word problems or real-life application problems (Belhu, 2017; DeCorte et al., 1985). According to Österholm(2006), "there is a complex relationship between comprehension and problemsolving”. Polya (1990) cited in Mustafa (2017), found out that reading comprehension process is followed by planning for solution and planning implementation steps.

\section{Individual Factors}

Socio-economic status (financial constraints), absenteeism from lectures, motivation and students' attitude towards mathematics were categorized under individual factors.

Socio-economic status: According to William (2002), social economic status is most commonly determined by combining parents' level of education, professional status and income. The socio-economic status in this study refers to the financial constraints on students and their parents alike. The data gathered from the interview show that socio-economic status of the student is a contributing factor in the teaching and learning of mathematics. According to the students, the financial constraints makes them loose concentration during lessons. They shared the view that coming to school with all these financial challenges does not only de-motivate you but makes you lose concentration during teaching and learning processes. 
ISSN 2250-3153

Families where parents are socially, educationally and economically advantageous promote a high level of achievement in their children (Considene \& Zappala, 2002) and the educational status of any person depends strongly on the person's socio-economic status (Graetz, 1995).

The challenges associated with this factor are lack of concentration on the part of the students, de-motivation and poor performance in mathematics. It is obvious that if students loose concentration in the classroom, it will be difficult to get the conceptual understanding of the subject matter and will definitely lead to poor academic performance in the subject.

Absenteeism from lectures: Absenteeism a tendency to be away from work or school without a good reason. The results from the study revealed that due to poor socio-economic status of the students coupled with economic hardship in the country, some of the students are forced to sponsored themselves in their education. The situation has forced some of the students to sometimes go out and look for petty jobs to get money to feed themselves while on campus. Some even go the extent of looking for money to come and pay the remaining of their unfinished school bills. Some of them have had recourse to parttime work inside or outside the university. Class participation is the only way to measure student learning skills according to Khalid and Khalid (2017). Students miss valuable information when they are not in the classroom. They also missed the interaction lecturer and the benefits of specific examples used to clarify difficult concepts.

\section{Conclusion and Recommendations}

The study identified five categories of factors affecting teaching and learning of mathematics in the undergraduate level. These factors include pedagogical factors, conceptual factors, technological factors, modelling factors and individual factors with the pedagogical factors being the most influential of all. The pedagogical factors include instructional strategies and methods, teacher's knowledge in computer and computer applications for mathematics, perception of teachers on the usefulness of computer in instructional delivery and motivation. The conceptual factors include the students' ability to recall some pre-requisite knowledge and students' computational ability. The technological factors include students' knowledge in computer and computer application for mathematics, the availability of ICT tools, teachers and students' knowledge in computer and computer application for mathematics and the availability of computer application for mathematics. Comprehension and computational ability were classified as the modelling factors. Other modelling factor includes computer application to Mathematics. Socio-economic status (financial constraints), absenteeism from lectures, motivation and students' attitude towards mathematics were categorized under individual factors. It was realized from the study that if these factors are not minimized, it will lead to poor performance in mathematics.

\section{References}

[1]. Alfred, K., Linety, M., \& Symon, C. K. (2012). Factors inhibiting acquisition of mathematical knowledge in kenyan institutions of higher learning. The International Institute for Science, Technology and Education (IISTE), 2(9), 94-104.

[2]. Amuchie, A. A. (2015). Availability and Utilization of ICT Resources in Teaching and Learning in Secondary Schools in ArdoKola and Jalingo, Taraba State. Journal of Poverty, Investment and Development. Vol. 8

[3]. Bed, R. A. (2017). Factors affecting difficulties in learning mathematics by mathematics learners. International Journal of Elementary Education, 6(2), 8-15. Retrieved from www.sciencepublishinggroup.com $/ \mathrm{j} / \mathrm{ijeedu}$ doi:10.11648/j.ijeedu.20170602.11

[4]. Belhu, H. S. (2017). Factors affecting learning mathematics in the case assosa university college of natural science. International Journal of Education, Culture and Society, Vol 2 (1), 6-12. doi: 10.11648/j.ijecs.20170201.12

[5]. Bibi, A., Sharifa, N. S. Z., Nabeel, A. M. A., Mushtaq, A., \& Umbreen, S. (2017). Factors affecting differential equation problem solving ability of students at pre-university level: A conceptual model. Malaysian Online Journal of Educational Sciences, 5(4), 13 24.

[6]. Bloom, B., Englehart, M., Furst, E., Hill, W., \& Krathwohl, D. (1956). Taxonomy of educational objectives: The classification of educational goals. handbook i: Cognitive domain. New York, Toronto: Longmans, Green.

[7]. Carr, M. (1996). Motivation in mathematics. Hampton Press Inc. New York.

[8]. Considine, G. \& Zappala, G. (2002). Influence of social and economic disadvantage in the academic performance of school students in Australia. Journal of Sociology, (38) 129-148.

[9]. DeCorte, E., Verschaffel, L., \& DeWin, L. (1985). Influence of rewording verbal problem on children's problem representations and solutions. Journal of Educational Psychology, 77(4), 460-470.

[10]. Dursan, S. and Dede, Y. (2004). The Factors Affecting Students Success in Mathematics: Mathematics Teachers Perspective. Journal of Gazi Education Faculty, Vol. 24(2), pp. 217-230.

[11]. Gunaseelan, B., \& Pazhanivelu, G. (2016, July). Identifying factors affecting the mathematics achievement of students for better instructional design. International Journal of Development Research, 6(7), 8804-8809. Retrieved from https://www.journalijdr.com/identifying-factors-affectingmathematics-achievement

[12]. Hue, L.T., Ab Jalil, H. (2013): Attitudes towards ICT Integration into Curriculum and Usage among University Lecturers in Vietnam. International Journal of Instruction, 6(2),53-66.

[13]. Justice, E., Osei, K. A., Daniel, N. (2015). Factors influencing students' mathematics performance in some selected colleges of 
education in Ghana. International Journal of Educational Learning and Development. Vol. 3(3), pp. 68-74

[14]. Khalid, N. and Khalid, M. (2017). Effect of Absenteeism on students performance. International Journal of Science and Research Publications. Vol. 7(9), 151-167

[15]. Leongsan, J.B. (2003). Assessing the Mathematics Achievement of College Freshman using Paget's Logical Operation, Hawaii International Conference on Education, Waikiki, Hawaii, USA.

[16]. Mewcha, A. G. \& Ayele, A. F. (2015). Assessing Teacher's Perception on Integrating ICT in Teaching-Learning Process: The case of Adwa College. Journal of Education and Practice. Vol. 6(4) pp. 114-124

[17]. Metodički, O. (2011). Application of computers in initial teaching of mathematics. Primena Računra U Pačetnoj Nastavi Mathematike: Review Article, 6(1), 105-117.

[18]. Michael, O. J. T. (2006). Teachers using computers in mathematics: a longitudinal study. In Novotná, J., Moraová, H., Krátká, M. \& Stehlíková, N. (Eds.). Proceedings 30th Conference of the International Group for the Psychology of Mathematics Education, Vol. 5, pp. 265-272.

[19]. Mohammed, Z. G. A., Mamat, M. B., Abdullah, L., \& Maad, H. A. (2012). The factors influence students' achievement in mathematics: A case for Libyan's students. World Applied Sciences, 17(19), 12241230.
[20]. Murray, J. (2013, August). The factors that influence mathematics achievement at the berbice campus. International Journal of Business and Social Sciences, 4(10), 150-164.

[21]. Mustafa, U. (2017). The effect of reading comprehension and problem solving strategies on classifying elementary 4th grade students with high and low problem solving success. Journal of Education and Training Studies, 5(6), 44-63.

[22]. Olive, J. F. A. (2014). Factors that affect mathematics achievements of students of Philippine Normal University - Isabela Campus, International Refereed Research Journal, Vol 5(4), p. 83

[23]. Österholm, M. (2006). Characterizing reading comprehension of mathematical texts. Educational Studies in Mathematics., 136-145.

[24]. Polya, G. (1990). How to solve it? New York.

[25]. Rohrer, D., \& Pashler, H. (2007). Increasing retention without increasing study time. Association for Psychological Science, 16(4), 183-186.

[26]. Tukur, M. Y. and Abimbola, N. G. A. (2013). Factors Influencing Effective Learning of Mathematics at Senior Secondary Schools within Gombe Metropolis, Gombe State Nigeria. Journal of Education and Practice, Vol.4(25) pp. 61-66

[27]. William, H. J. (2002). Examining the Effects of Parental Absence on the Academic Achievement of Adolescents: The Challenge of Controlling for Family Income. Journal of Families and Economic Issues. Vol. 23(2):189-210. DOI: 10.1023/A:1015790701554

\section{Author's Biography}

Ali Mohammed, PhD (Mathematics Education), University of Education, Winneba, Ghana, West Africa, Tel: +233 20831 5368,

E-Mail: mali@uew.edu.gh 